\title{
Pemahaman Konsep Awal Calon Guru Sekolah Dasar Tentang Pecahan
}

\author{
Lisnani \\ Pendidikan Guru Sekolah Dasar, Universitas Katolik Musi Charitas \\ Jalan Bangau No. 60, Palembang, Sumatera Selatan, Indonesia \\ lisnani@ukmc.ac.id
}

Artikel diterima: 24-10-2018, direvisi: 24-01-2019, diterbitkan: 31-01-2019

\begin{abstract}
Abstrak
Tujuan dari penelitian ini adalah mengetahui gambaran proses pembelajaran pecahan menggunakan konteks puding dan bangun datar segitiga sama sisi dan mengetahui pemahaman konsep awal calon guru sekolah dasar tentang pecahan. Jenis penelitian yang digunakan dalam penelitian ini adalah penelitian kualititatif-kuantitatif. Subjek dari penelitian ini adalah calon guru SD Program Studi PGSD Semester III berjumlah 19 orang tahun akademik 2018/2019. Teknik pengumpulan data menggunakan wawancara terkait dengan pemahaman calon guru SD tentang pecahan dan tes. Hasil dari penelitian ini adalah sebagai berikut: 1) gambaran proses pembelajaran pecahan menggunakan konteks puding dan bangun datar segitiga sama sisi menunjukkan perbedaan jawaban antara calon guru SD yang satu dengan yang lain; 2) pemahaman konsep calon guru SD terhadap materi pecahan masih tergolong rendah sebesar 33,82\%; 3) hasil wawancara menunjukkan bahwa calon guru SD terbantu (sebanyak 60\%) melalui penggunaan konteks di dalam pembelajaran pecahan.

Kata Kunci: pecahan, PMRI, konteks, pemahaman konsep.
\end{abstract}

\section{Understanding of the Basic Concept of the Basic School Teachers about Fraction}

\begin{abstract}
The purpose of this study was to find out the description of the fraction learning process using the context of the pudding and to construct a flat equilateral triangle and to know the understanding of the initial concept of the elementary school teacher about fractions. The type of research used in this study is qualitative-quantitative research. The subjects of this study were 19th semester students of the PGSD Study Program in the 2018/2019 academic year. Data collection techniques used interviews related to the understanding of prospective elementary school teachers about fractions and tests. The results of this study are as follows: 1) description of the fraction learning process using the context of pudding and the flat build of equilateral triangles showing differences in answers between elementary school teacher candidates with one another; 2) the understanding of students' concepts of fraction material is still relatively low at 33.82\%; 3) the results of interviews indicate that elementary school teacher candidates are helped (as much as 60\%) through the use of context in fraction learning.

Keyword: fractions, PMRI, context, conceptual understanding.
\end{abstract}




\section{Pendahuluan}

Pembelajaran matematika di berbagai jenjang pendidikan mulai dari Taman Kanak-Kanak sampai Perguruan Tinggi telah banyak memberikan kontribusi yang mendasar bagi perkembangan dan kemajuan intelegensi siswa (Sipayung, 2018: 402). Hal ini sejalan dengan tujuan pembelajaran matematika yang hendak dicapai, kemampuan pemahaman konsep menjadi kompetensi yang esensial dan merupakan visi dari belajar matematika (Gardenia, 2016: 110).

Ruang lingkup matematika SD ada tiga yaitu bilangan (bilangan cacah, bulat, prima, pecahan, kelipatan dan faktor, pangkat dan akar sederhana), geometri dan pengukuran (bangun datar dan bangun ruang, hubungan antar garis, pengukuran (berat, panjang, luas, volume, sudut, waktu, kecepatan, dan debit, letak dan koordinat suatu benda), serta statistika (menyajikan dan menafsirkan data tunggal) dalam penyelesaian masalah kehidupan sehari-hari.

Kurangnya pemahaman terhadap konsep pecahan, desimal dan persen akan berpengaruh terhadap siswa dalam mengembangkan pengetahuan penalaran proposional dan topik-topik aljabar maupun probabilitas (Behr, dkk., 2015). Pecahan adalah salah satu topik penting bagi siswa sebagai dasar mempelajari aljabar dan yang lainnya, namun pada kenyataanya masih banyak yang belum memahaminya (Yulianingsih, Febrian, dan Dwinata, 2018).
Padahal konsep pecahan sudah dipelajari sejak kelas III SD seharusnya menjadi pemahaman dasar yang harus dikuasai oleh siswa, karena sebagai bekal prasyarat untuk mempelajari materi operasi hitung pecahan pada tingkatan selanjutnya. Konsep pecahan merupakan topik yang lebih sulit dibandingkan dengan bilangan bulat. mempelajari konsep pecahan sangat Memungkinkan terjadinya miskonsepsi pada diri siswa. Kesulitan siswa dalam memahami konsep pecahan diduga karena mereka sulit mencerna secara real (Kania, 2018: 3).

Maka dari itu, seorang calon guru SD perlu harus memahami konsep awal tentang pecahan. Namun, pada kenyataan ada berbagai kesulitan yang dihadapi oleh calon guru SD dalam memahami tentang pecahan. Hal ini sejalan dengan kurikulum di setiap Program Studi PGSD umumnya terdapat mata kuliah Matematika yang harus ditempuh oleh calon guru SD.

Hal ini kembali dipertegas dalam National Council of Teacher of Mathematics (NCTM, 2000) yang menyatakan bahwa peserta didik dalam belajar matematika harus disertai dengan pemahaman. Peneliti melakukan pengambilan data awal dalam bentuk wawancara terkait dengan materi pecahan kepada calon guru sekolah dasar. Selanjutnya, peneliti memberikan tes awal terkait pemahaman konsep calon guru SD pada materi pecahan. Hasil yang diperoleh adalah pemahaman konsep calon guru SD tergolong minim. 
Permasalahan yang sama terkait dengan pecahan juga dialami oleh calon guru SD baru 2015 di salah satu perguruan tinggi. Hal ini terbukti dari hasil tes kemampuan calon guru SD terkait dengan pecahan terlihat bahwa $83 \%$ calon guru SD tidak mampu melakukan operasi penjumlahan dan pengurangan pecahan karena kesulitan menyamakan penyebut dengan menggunakan KPK (Edo, 2016).

Rendahnya pemahaman konsep calon guru SD dikarenakan calon guru SD tidak memahami konsep dasar pecahan dan kurangnya pendekatan yang memadai saat pembelajaran pecahan berlangsung. Maka dari itu, calon guru SD harus konsep pecahan dengan baik, memahami cara menyampaikan pecahan sebagai sesuatu yang menarik, dengan menunjukan contoh konkrit, serta memiliki kesungguhan untuk membantu siswa dalam memahami konsep dan aplikasi pecahan secara mendalam (Suwarto, 2018: 328).

Pemahaman konsep adalah kemampuan untuk menangkap makna dan arti dari bahan yang dipelajari untuk menggolongkan sekumpulan objek. (Asyhuri, 2016: 59). Seseorang dikatakan memiliki pemahaman konsep matematika berdasarkan indikator pemahaman konsep yang diberikan. Menurut Pranata (2016), indikator pemahaman konsep matematika yaitu: 1) menyatakan ulang sebuah konsep; 2) mengklasifikasikan objek-objek menurut sifat-sifat tertentu (sesuai dengan konsepnya); 3) memberikan contoh dan noncontoh dari konsep; 4) menyajikan konsep dalam berbagai bentuk representasi

matematika;

mengembangkan syarat perlu atau syarat cukup suatu konsep; 6) menggunakan, memanfaatkan, dan memilih prosedur atau operasi tertentu; 7) mengaplikasikan konsep atau algoritma pemecahan masalah.

Petit, Laird, dan Marsden (2010) mengemukakan bahwa "pembelajaran pecahan akan lebih baik menggunakan model kontekstual". Hal ini sejalan dengan pendapat Van de Walle (2008) yang mengatakan bahwa "Pendekatan untuk membantu siswa memahami pecahan adalah menyuruh mereka menggunakan model atau benda konkrit untuk menemukan pecahan-pecahan yang berbeda".

Untuk meningkatkan pemahaman konsep di dalam pembelajaran pecahan, sebagian besar peneliti menggunakan media pembelajaran berupa alat peraga. Menurut Sugiarto (2010), satu hal yang perlu mendapat perhatian adalah teknik penggunaan alat peraga dalam pembelajaran matematika secara tepat. Selain penggunaan media, proses pembelajaran pecahan juga harus didukung dengan pendekatan pembelajaran yang sesuai. Maka dari itu, peneliti mencari solusi agar dapat meningkatkan pemahaman konsep awal calon guru SD. Solusi tersebut adalah menggunakan pendekatan untuk menumbuhkan pemahaman konsep calon guru SD tentang pecahan yaitu penggunaan pendekatan Pendidikan Matematika Realistik Indonesia (PMRI).

\section{Mosharafa: Jumal Pendidikan Matematika}


Tujuannya agar calon guru SD memahami konsep pecahan secara nyata.

Menurut Suryanto (2010: 38), PMRI merupakan suatu inovasi pendidikan matematika atau inovasi pendekatan pembelajaran matematika yang sejalan dengan teori konstruktivisme. PMRI telah digunakan sejak 2001 sebagai upaya memperbaiki minat, sikap, dan hasil belajar siswa (Darmowijoyo, Kiki, dan Zulkardi, 2017: 155). Sebuah prinsip penting PMRI adalah keterlibatan dalam matematika untuk siswa harus dimulai dengan konteks bermakna (Sarbiyono, 2016).

Karakteristik PMRI menurut Sembiring, Hoogland, dan Dolk (2010:160) diantaranya sebagai berikut: 1) penggunaan konteks pada eksplorasi; 2) penggunaan model; 3) Penggunaan kreasi dan kontribusi siswa. 4) interaktifitas.; 5) keterkaitan; 6) menggunakan karakteristik alam dan budaya Indonesia. Penelitian yang dilakukan oleh peneliti melalui pendekatan PMRI dengan penggunaan konteks yang ada di sekitar kita. Seperti penggunaan agar-agar (puding) dan bangun datar untuk menggali pemahaman konsep calon guru SD tentang pecahan secara utuh dan menyeluruh.

Yang menjadi rumusan masalah dalam penelitian ini adalah: 1) bagaimana gambaran proses pembelajaran pecahan menggunakan benda konkret di sekitar calon guru SD?; 2) bagaimana pemahaman konsep calon guru SD terhadap materi pecahan?.
Berdasarkan latar belakang tersebut, peneliti tertarik melakukan penelitian yang berjudul "Pemahaman Konsep Awal Calon Guru Sekolah Dasar Tentang Pecahan"

\section{Metode}

Penelitian ini menggunakan metode penelitian kualitatif-kuantitatif berupa penelitian deskriptif. Penelitian ini dikatakan penelitian kualitatif karena memberikan gambaran pemahaman konsep awal calon guru sekolah dasar tentang pecahan menggunakan konteks puding dan segitiga sama sisi. Pada hasil penelitian ini akan dikemukakan gambaran proses pembelajaran pecahan menggunakan benda konkret di sekitar calon guru SD Pada awal pembelajaran, peneliti meminta calon guru SD membawa puding untuk dijadikan konteks dalam penelitian ini. Sedangkan penelitian ini dikatakan kuantitatif karena menggunakan tes untuk mengukur pemahaman konsep calon guru SD. Data hasil tes akan dianalisis Teknik pengumpulan data menggunakan lembar wawancara dan tes. Tes yang diberikan terdiri dari pretest dan posttest. Teknik analisa data menggunakan uji independent sample t-test untuk menganalisa hasil pretest dan posttest calon guru sekolah dasar. Tujuan pemberian tes adalah untuk mengetahui bagaimana pemahaman konsep calon guru sekolah dasar. 


\section{Hasil dan Pembahasan}

\section{A. Gambaran Proses Pembelajaran Pecahan}

Pada hasil penelitian ini akan dikemukakan gambaran proses pembelajaran tentang pecahan menggunakan benda konkret di sekitar calon guru SD. Pada tahap awal pembelajaran, peneliti meminta calon guru SD membawa puding untuk dijadikan konteks dalam penelitian ini.
Lalu, perwakilan salah satu kelompok yaitu kelompok 1 diminta maju ke depan kelas sambal membawa puding. Selanjutnya, peneliti meminta calon guru SD membagi puding menjadi ukuran yang sama besar sebanyak 32 potong. Namun, sebelumnya calon guru SD harus memikirkan cara membagi puding tersebut menjadi beberapa ukuran yang sama besar seperti gambar 1 berikut.

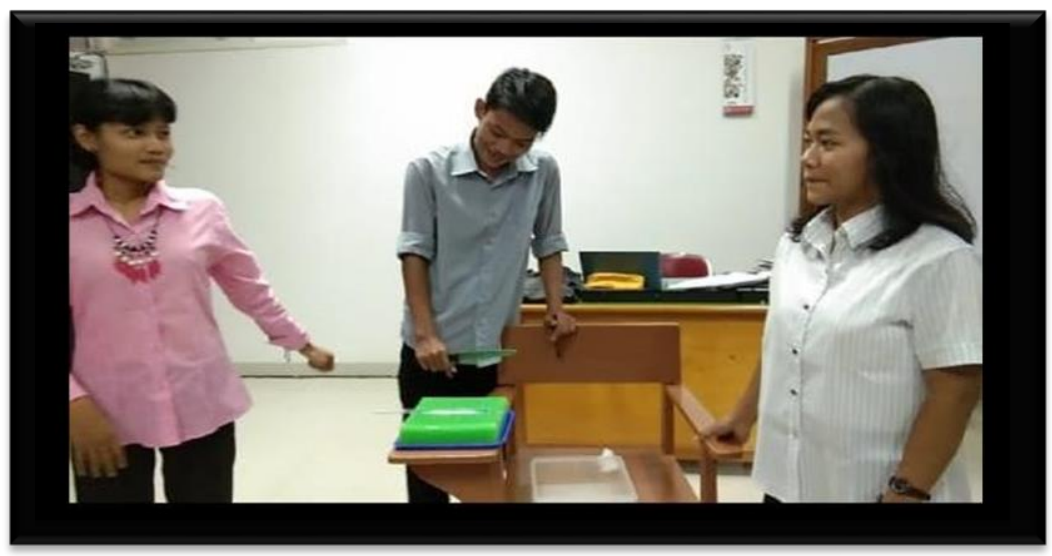

Gambar 1. Calon guru SD menjelaskan ukuran puding.

Gambar 1 menunjukkan bahwa calon guru SD di kelompok lain guru SD menjelaskan ukuran puding $21 \mathrm{~cm}$ mennggambarkan hasil dari setiap x $21 \mathrm{~cm}$. Selanjutnya, calon guru SD potongan puding sehingga diperoleh memikirkan cara membagi puding dengan proses pemotongan seperti gambar 2 . ukuran yang sama rata. Sedangkan calon

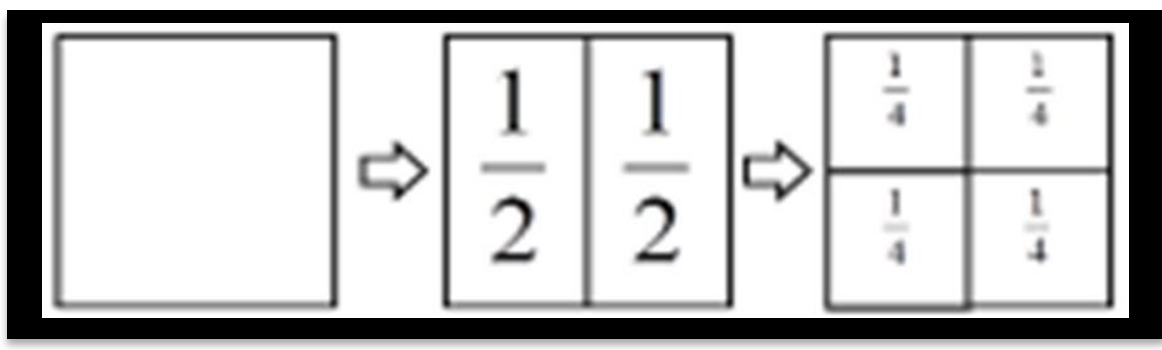

Gambar 2. Sketsa potongan puding 
Gambar 2 menunjukkan sketsa dari hasil pemotongan pudding dideskripsikan menjadi beberapa bagian mulai dari $\frac{1}{2}$, $\frac{1}{4}$, dan seterusnya. Pada akhirnya, diperoleh hasil yang diinginkan oleh peneliti seperti pada gambar 3 .

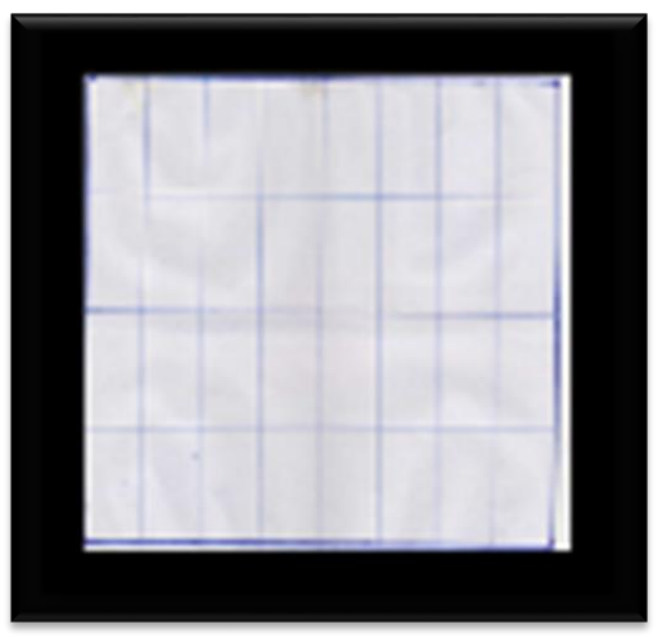

Gambar 3. Hasil akhir pemotongan puding.

Berdasarkan gambar 3 diperoleh hasil pemotongan pudding sebanyak 32 buah. Hal ini menunjukkan bahwa pecahan mengandung makna membagi sesuatu dengan ukuran yang sama. Namun, ada juga yang membuat ukuran yang tidak sama seperti pada gambar 4 berikut.

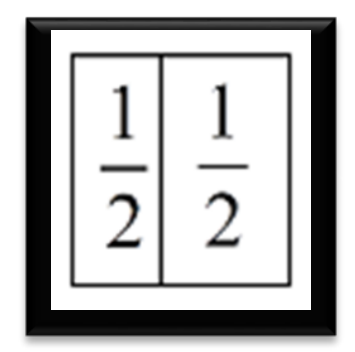

Gambar 4. Kesalahan calon guru SD dalam membagi ukuran sketsa puding.
Gambar 4 menunjukkan bahwa sketsa yang dibuat calon guru SD memiliki ukuran yang tidak sama sehingga sketsa tersebut tidak dapat dikatakan sebagai pecahan.

Setelah selesai dengan puding, konteks berikutnya yang digunakan adalah bangun datar berbentuk segitiga sama sisi dengan ukuran $20 \mathrm{~cm} \times 20 \mathrm{~cm}$. Calon guru SD diminta untuk membuat kemungkinan banyaknya segitiga sama sisi yang dihasilkan. Hasil kerja calon guru SD disajikan seperti pada gambar 5, gambar 6, dan gambar 7.

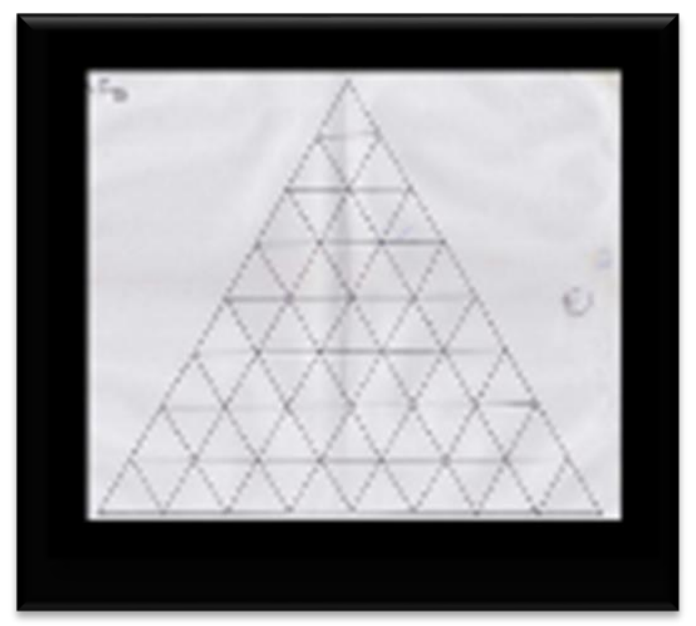

Gambar 5. Hasil kerja calon guru SD berinisial KS.

Gambar 5 menunjukkan hasil dari segitiga sama sisi berukuran kecil sebanyak 64 buah. 


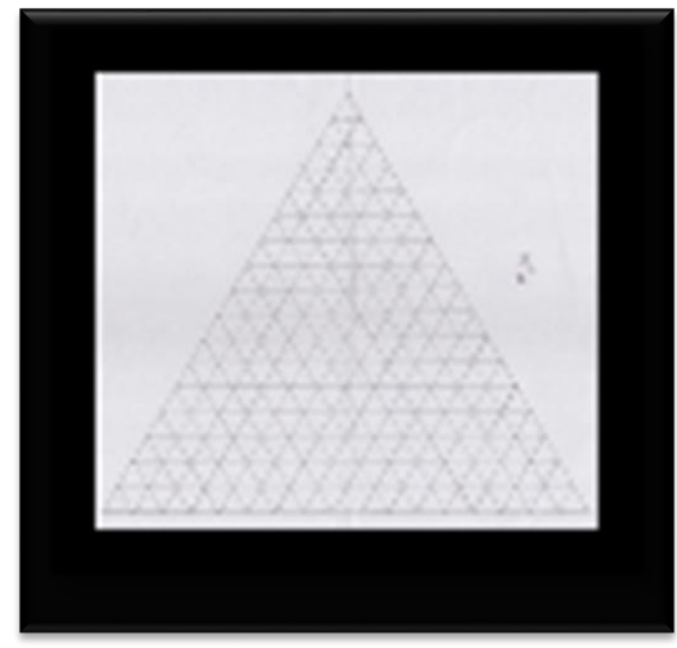

Gambar 6. Hasil kerja calon guru SD berinisial MR.

Gambar 6 menunjukkan hasil dari segitiga sama sisi berukuran kecil sebanyak 291 buah.

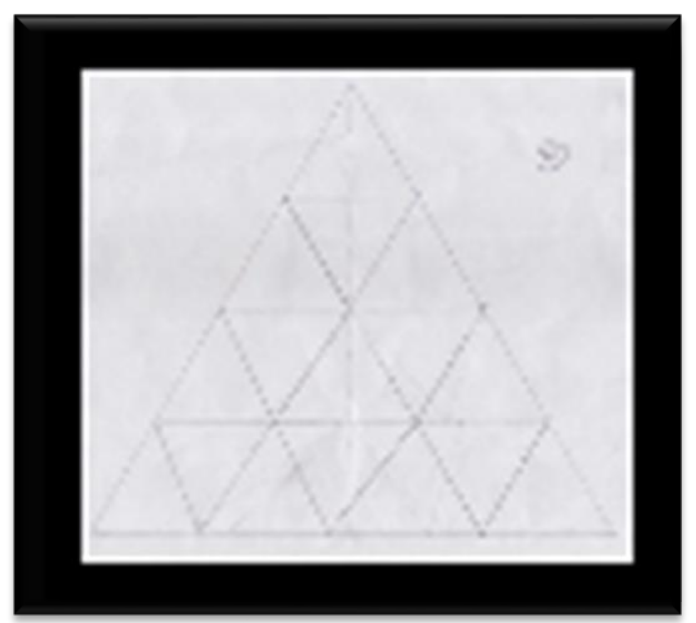

Gambar 7. Hasil kerja calon guru SD berinisial AM.
Gambar 7 menunjukkan hasil dari segitiga sama sisi berukuran kecil sebanyak 16 buah. Perbedaan jawaban calon guru SD tersebut menunjukkan bahwa tingkat pemahaman calon guru SD yang berbeda. Di samping itu, penggunaan konteks membantu calon guru SD menemukan secara langsung konsep dari pecahan.

\section{B. Pemahaman Konsep Calon Guru SD terhadap Materi Pecahan}

Setelah mendeskripsikan gambaran proses pembelajaran pecahan menggunakan benda konkret di sekitar calon guru SD, Selanjutnya, peneliti ingin mengetahui pemahaman konsep calon guru SD terhadap materi pecahan menggunakan serangkaian soal pada tes awal yang telah dijawab calon guru SD.

Hasil tes awal yang dilaksanakan oleh peneliti pada calon guru SD semester III Tahun Akademik 2018/2019 dengan soal yang berbentuk uraian berjumlah sepuluh soal pada materi pecahan ditunjukkan hasil tes kemampuan pemahaman konsep calon guru SD masih rendah masih banyak yang calon guru SD yang kurang memahami tentang pecahan. Hasil tes awal calon guru SD seperti pada tabel 1 berikut.

Tabel 1.

Hasil Tes Pemahaman Konsep

\begin{tabular}{clc}
\hline Nomor & \multicolumn{1}{c}{ Pernyataan } & Tabel \\
\hline 1 & $\begin{array}{l}\text { Menyatakan ulang sebuah } \\
\text { Konsep }\end{array}$ & $52 \%$ \\
\hline 2 & $\begin{array}{l}\text { Mengklasifikasikan objek } \\
\text { menurut sifat sesuai dengan } \\
\text { konsepnya }\end{array}$ & $28,13 \%$ \\
\hline 3 & Memberikan contoh dan noncontoh & $31,12 \%$
\end{tabular}




\begin{tabular}{|c|lc|}
\hline 4 & $\begin{array}{l}\text { Menyajikan konsep dalam } \\
\text { berbagai bentuk representasi } \\
\text { matematika }\end{array}$ & $37,22 \%$ \\
\hline 5 & $\begin{array}{l}\text { Mengembangkan syarat perlu atau syarat cukup suatu } \\
\text { Konsep }\end{array}$ & $38,12 \%$ \\
\hline 6 & $\begin{array}{l}\text { Menggunakan, memanfaatkan dan memilih } \\
\text { prosedur tertentu }\end{array}$ & $29,12 \%$ \\
\hline 7 & $\begin{array}{l}\text { Mengaplikasikan konsep atau } \\
\text { algoritma dalam pemecahan } \\
\text { masalah }\end{array}$ \\
\hline
\end{tabular}

Berdasarkan Tabel 1 dapat diketahui bahwa calon guru SD mampu menyatakan ulang sebuah konsep dalam kategori sedang sebesar 52\%, mampu mengklasifikasikan objek menurut sifat sesuai dengan konsepnya dalam kategori rendah yakni sebesar 28,13\%, mampu memberikan contoh dan non-contoh dalam kategori rendah sebesar 31,12\%, mampu menyajikan konsep dalam berbagai bentuk representasi matematika dalam kategori rendah sebesar 37,22\%, mampu mengembangkan syarat perlu atau syarat cukup suatu konsep dalam kategori rendah sebesar 38,12\%, mampu menggunakan, memanfaatkan dan memilih prosedur tertentu dalam kategori rendah sebesar 29,12\%, mampu mengaplikasikan konsep atau algoritma dalam pemecahan masalah dalam kategori rendah sebesar $21,05 \%$. Skor rata-rata yang diperoleh pada pemahaman konsep hanya $33,82 \%$.

\section{Hasil Tes Calon Guru SD}

Calon guru SD diberikan tes awal (pretest) untuk mengetahui pemahaman konsep awal tentang pecahan berupa soal essai sebanyak 10 soal essai. Selanjutnya diberikan tes akhir (posttest) dengan jumlah soal yang sama. Hasil pretest dan posttest dihitung dengan menggunakan SPSS seperti tabel 2.

Tabel 2.

Hasil Pretest dan Posttest

\begin{tabular}{lrrrr|}
\hline & N & Mean & $\begin{array}{c}\text { Std. } \\
\text { Deviation }\end{array}$ & $\begin{array}{c}\text { Std. Error } \\
\text { Mean }\end{array}$ \\
\hline pretest & 19 & 53.06 & 7.709 & 1.285 \\
\hline posttest & 19 & 78.56 & 17.313 & 2.885 \\
\hline
\end{tabular}

Tabel 2 menunjukkan hasil nilai pretest dan posttest calon guru sekolah dasar mengalami peningkatan sebesar 25,50 dari 53,06 menjadi 78,56.

\section{Penutup}

Melalui penggunaan konteks berupa puding dan bangun datar berupa segitiga sama sisi diperoleh gambaran proses pembelajaran pecahan yang dialami calon guru SD. Calon guru SD mempunya pola pikir yang berbeda-beda dalam menyelesaikan soal pecahan berkonteks puding dan segitiga sama sisi. Berdasarkan hasil tes awal dapat ditarik kesimpulan bahwa hanya indikator menyatakan ulang sebuah konsep sudah dikuasai oleh calon guru SD. 
Berdasarkan hasil tes awal terkait dengan pemahaman konsep calon guru SD secara keseluruhan membuktikan bahwa kemampuan pemahaman konsep matematika calon guru SD di Program Studi PGSD Universitas Katolik Musi Charitas tentang pecahan tergolong masih rendah sebesar 33,82\%.

Setelah menggunakan pendekatan PMRI menggunakan konteks puding dan bangun datar segitiga sama sisi terjadi peningkatan hasil belajar sebesar 25,50.

Peranan peneliti selaku dosen sangat dibutuhkan dalam memberikan pengetahuan kepada calon guru SD agar dapat meningkatkan pemahaman konsep calon guru SD. Dengan kata lain, peneliti harus menggunakan pendekatan yang tepat.

Penelitian ini akan dijadikan menjadi tolak ukur awal untuk penelitian lanjutan terkait dengan usaha yang dilakukan peneliti dalam meningkatkan pemahaman konsep calon guru SD terkait materi pecahan.

\section{UCAPAN TERIMA KaSIH}

Peneliti mengucapkan kepada seluruh calon guru SD yang bersedia menjadi subjek penelitian di dalam penelitian ini. Di samping itu, Peneliti juga mengucapkan terima kasih kepada Universitas Katolik Musi Charitas yang telah mendukung Peneliti di dalam penelitian ini.

\section{DAfTAR PUSTAKA}

Behr, M., Wachsmuth, I., dan Post, T. (2015). Construct a sum: A measure of children's understanding of fraction size. Journal for Research in Mathematics Education, 16 (2), 120131

Darmowijoyo, Kiki R.P., dan Zulkardi. (2017). Pembelajaran Pecahan dengan Menggunakan Manik Susun. JRPM, 2(2) 153-166.

Edo, S. I. (2016). Jenis kekeliruan akibat menghafal prosedur rutin dalam melakukan operasi penjumlahan dan pengurangan pecahan. Mosharafa: Jurnal Pendidikan Matematika, 5(3), 223-233.

Gardenia, N. (2016). Peningkatan Kemampuan Pemahaman dan Komunikasi Matematis Siswa SMK Melalui Pembelajaran Konstruktivisme Model Needham. Jurnal Formatif, 6 (2) $110-118$.

Kania, N. (2018). Alat Peraga untuk Memahami Konsep Pecahan. Jurnal THEOREMS (The Original Research of Mathematics), 2 (2) 1-12.

National Council of Teachers of Mathematics (2000). Principles and Standars for School Mathematics. Reston, VA: NCTM.

Petit, M., Laird, R. E., and Marsden, E. L. (2010). A focus on fractions: Bringing research to the classroom. New York and London: Routledge Taylor \& Tracis Group.

Pranata, E. (2016) Implementasi Model Pembelajaran Group Investigation (GI) Berbantuan Alat Peraga Untuk Meningkatkan Kemampuan Pemahaman Konsep Matematika. 
Jurnal Pendidikan Matematika

Indonesia, 1(1) 34-38.

Sarbiyono, S. (2016). Penerapan

Pendekatan Matematika Realistik

Terhadap Kemampuan Pemecahan

Masalah Matematis Siswa. JRPM

(Jurnal Review Pembelajaran

Matematika), 1(2), 163-173.

doi:10.15642/jrpm.2016.1.2.

Sembiring, R.K., Hoogland, K. \& Dolk, M. (2010). A decade of PMRI in Indonesia. Bandung-Utrecht: APS International.

Sipayung, A. (2018) Peningkatan

Pemahaman Konsep Matematika

Tentang Sifat-Sifat Bangun Ruang

Sederhana Melalui Contextual

Teaching and Learning. Mosharafa:

Jurnal Pendidikan Matematika, 7 (3)

401-412.

Sugiarto (2010). Bahan Ajar Workshop

Pendidikan Matematika I. Semarang:

Jurusan matematika UNNES.

Suryanto. (2010). Pendidikan Matematika realitik Indonesia (PMRI). Jakarta: IPPMRI.

Suwarto. (2018). Konsep Operasi Bilangan Pecahan Melalui Garis Bilangan. Mosharafa: Jurnal Pendidikan Matematika, 7 (3) 327-336.

Van de Walle, J. A. (2008). Sekolah Dasar dan Menengah Matematika Pengembangan Pengajaran Jilid 2 (6 ed.). Jakarta: Erlangga.

Yulianingsih, A., Febrian, Dwinata, A. (2018). Analisis Kesalhan konsep pecahan pada siswa kelas VII A SMP Negeri 13 Satu Atap Tanjungpinang. Mosharafa: Jurnal Pendidikan Matematika, 7 (2), 199-206.

\section{Riwayat Hidup PENULIS}

Lisnani, S.Pd., M.Pd.

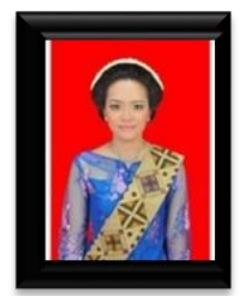

Lahir di Palembang, 19 September 1987.

Sekretaris Program Studi PGSD di Universitas Katolik Musi Charitas. Studi: S1 Pendidikan Fisika di Universitas PGRI Palembang, tahun 2006 dan lulus tahun 2010; S2 Pendidikan Matematika di Universitas Sriwijaya Palembang, Sumatera Selatan. Pada tahun 2016 mengikuti SEMIRATA 2016 BIDANG MIPA BKS - PTN BARAT Peran MIPA Dalam Meningkatkan Daya Saing Bangsa Menghadapi Masyarakat Ekonomi ASEAN; menjadi pemakalah pada The $1^{\text {st }}$ International Conference On Law, Economics, and Education "Building Mutually Beneficial Cooperation to Facing ASEAN Economic Community". Pada tahun 2017 menjadi pemakalah pada International Conference on Mathematic and Natural Science. Pada bulan Mei 2017, Peneliti juga menulis di Suska: Journal of Mathematics dengan judul "Desain Materi Bangun Datar Menggunakan Origami Berkonteks Tangram Di SD Kelas II". Pada bulan April 2018, Peneliti juga mendapatkan Hibah Penelitian Dosen Pemula (PDP) dari Ristekdikti dengan Judul “Desain Buku Ajar Matematika Bilingual Materi Bangun Datar Menggunakan Pendekatan PMRI" dan hasil penelitian itu diterbitkan pada Jurnal Mosharafa; Jurnal Pendidikan Matematika dengan judul "Desain Buku Ajar Matematika Bilingual Materi Bangun Datar Menggunakan Pendekatan PMRI Berkonteks Kebudayaan Lokal". Pada tanggal 5 Mei 2018 menjadi pemakalah pada International Conference on Mathematics and Sciences Education; Pada bulan Juni 2018, hasil artikel peneliti tembus Scopus pada Jurnal IOP Conference Series dengan judul "Design Research on Plane Figure by Using Picture Story and Pairing Game to Improve Mathematical Communication Skills of Second Grade of Primary School Students". 